\title{
ClosTron-mediated engineering of Clostridium
}

Sarah A. Kuehne and Nigel P. Minton*

Clostridia Research Group; BBSRC Sustainable Bioenergy Centre; NIHR Biomedical Research Unit in GI Disease; University of Nottingham; Nottingham, UK

Keywords: ClosTron, Clostridium, group II intron re-targeting, mutant generation, metabolic engineering, virulence factor discovery

Submitted: 04/30/12

Revised: 06/01/12

Accepted: 06/05/12

http://dx.doi.org/10.4161/bioe.21004

*Correspondence to: Nigel Minton;

Email:nigel.minton@nottingham.ac.uk

Addendum to: Kuehne SA, Heap JT, Cooksley CM, Cartman ST, Minton NP. ClosTron-mediated engineering of Clostridium. Methods Mol Biol 2011; 765:389-407; PMID:21815105; http://dx.doi. org/10.1007/978-1-61779-197-0_23.
M embers of the genus Clostridium are of both medical and industrial importance. The molecular tools necessary to study and exploit their wide ranging physiological diversity through directed mutational analysis have until recently been lacking. The situation was transformed in the mid-2000s with the specific adaptation of intron re-targeting technology to the genus, through the development of the ClosTron. By making a handful of nucleotide changes to the group II intron encoding region, the intron can be directed to insert into almost any region within the genome. Through the use of a retrotranspositionactivated marker (RAM), based on the erm $B$ gene, successful insertion is selected on the basis of acquisition of resistance to erythromycin. The re-targeted region is designed using an online re-targeting algorithm (www.clostron.com), and then an order is placed with DNA2.0 for both the synthesis of the re-targeted region and its custom cloning into the ClosTron vector. Re-targeted ClosTrons are delivered ready for use in 10-14 days, allowing mutants to be isolated 5-7 days after receipt. Its availability has revolutionized clostridial molecular biology.

\section{Introduction}

Historically, the bacterial genus Clostridium is most often associated with disease. Thus, the term "clostridia" is to many synonymous with debilitating and life-threatening intoxications and disease such as botulism, tetanus, gangrene, antibiotic associated diarrhoea and food poisoning generally. ${ }^{1-3}$ However, the vast majority of clostridia are not only entirely benign, but in many instances possess properties and attributes of great benefit to mankind. This is because the genus occupies all manner of specialised niches and as a result has evolved a plethora of biocatalytic abilities which may be exploited for the production of specialist chemicals through an impressive array of biological transformations. As such, many species are being pursued as possible cell factories for the production of chemicals through processes that offer an alternative to traditional petro-chemical routes. ${ }^{4-6}$

One consequence has been the pressing need to develop gene tools and processes which may be deployed both to better understand the basis of a desirable catalytic pathway and to maximise its effectiveness in terms of productivity. Pivotal was the ability to make directed mutants in specific genes encoding the enzymes and regulators of a particular pathway. For many years, this most basic requirement proved to be extremely challenging. In common with the practices adopted in other bacteria, the scientific community had for many years focussed on the generation of mutants using classic recombination-based procedures. The successful implementation of such procedures had only limited success, with progress restricted mainly to certain strains of Clostridium perfringens. ${ }^{7}$ The landscape was transformed in the mid-2000s with the application of mobile group II intron re-targeting systems. ${ }^{8}$

\section{Mobile Group II Intron Re-Targeting}

The use of mobile group II introns in the generation of mutant alleles was pioneered by the Lambowitz laboratory through a series of elegant studies, which first 
defined the mechanisms by which bacterial introns move from one location to another and thereafter exploited the system to direct the insertion of the element to any intended target. ${ }^{9-11}$

Group II introns are catalytic RNAs that excise themselves from RNA transcripts via a lariat intermediate and insert themselves into a new distal target site. Bacterial group II introns tend to reside outside of structural genes (i.e., are exon-less) and are closely associated with mobile elements. ${ }^{12}$ Mobile group II introns carry an ORF specifying an Intron-Encoded Protein (IEP). The IEP exhibits remarkable multi-functionality. It mediates RNA splicing, participates in target site recognition, nicks the DNA target and inserts the spliced RNA molecule and finally synthesises the corresponding complementary DNA strand through reverse transcriptase activity. Thereafter host factors take over, removing the RNA strand through endonuclease activity and sealing the gaps via the participation of DNA ligase (see Fig. 1). ${ }^{12}$

Crucial to the exploitation of the system was the determination of the molecular basis of intron target site recognition.? Working with the group II intron from within the $\operatorname{lt} B$ gene of conjugative plasmids found in Lactococcus lactis (the " $L 1$. LtrB intron"), the Alan Lambowitz laboratory were able to show that the target specificity of the intron involves specific interactions between the ribonuclear protein (RNP) complex (composed of the IEP and the spliced RNA) and its target. Simplistically, a small number of amino acid residues within the IEP (encoded by $\operatorname{lt} A$ ) and up to 15 RNA nucleoside bases interact with complementary bases within the DNA target. Crucially, intron target specificity can be altered through the introduction of specific changes. ${ }^{12}$ This subsequently led to the formulation of an algorithm whereby the changes necessary to redirect the Ll.LtrB-derived introns to a gene of interest could be reliably predicted. ${ }^{10,13}$ A further pivotal finding was the demonstration that $\operatorname{ltr} A$ (encoding the IEP) need not be located within the intron, but could be provided in trans. This allows $\operatorname{ltr} A$ to be positioned on the backbone of the group II intron delivery plasmid. Loss of this plasmid from the cell following insertion of the group II intron into its target gene in the chromosome prevents both further mobility of the intron and importantly ensures that the insertion event is mutational by preventing LtrA-mediated splicing of the inserted intron sequence. ${ }^{12}$

The re-targeted introns that have resulted from these studies are called "TargeTrons." 11 Examples of these elements may be purchased from Sigma Aldrich as part of a kit which provides the template necessary to generate a small fragment of DNA (ca. 350 bp) by PCR which when substituted for the native L1.LtrB intron sequence in an appropriate vector re-directs the TargeTron to insert into the desired genome location. The primers needed to introduce the desired intron sequence changes are predicted using an online algorithm which is accessed on a "pay-per-click" basis at www.sigmaaldrich.co.uk.

TargeTron technology was first exemplified within the genus in the species C. perfringens following adaptation of the system's components (plasmid replicon, selectable marker and transcriptional signals) to ensure functionality in a clostridial background. In this instance, the gene inactivated was that encoding alpha-toxin $(p l c) .{ }^{14}$ Thereafter, basic TargeTrons have been used to generate mutants in Clostridium acetobutylicum and Clostridium phytofermentans affected in solvent production and substrate utilisation, respectively. ${ }^{15,16}$

\section{ClosTron Technology}

TargeTrons, such as that (pJIR750ai) used to generate the plc mutant in $C$. perfringens strain $13,{ }^{14}$ are disadvantaged by the lack of selection for successful insertion of the group II intron into the genome. Thus, following transformation of strain 13 with the re-targeted pJIR750ai plasmid, only two of the 38 transformant colonies obtained, were shown (by appropriate screening using PCR and primers that flanked the predicted insertion site) to contain cells in which the group II intron had successfully inserted into the plc gene. Subsequent phenotypic screening of the cell population within these positive colonies, based on the presence or absence of halos around colonies following serial dilution onto egg yolk BHI agar media, revealed that plc mutants represented around $10 \%$ of the population. ${ }^{14}$

The ClosTron has been developed based on the TargeTron as a specific tool to disrupt genes in Clostridia. ${ }^{8,17}$ To circumvent the above mentioned deficiencies, the ClosTron system incorporates, within the group II intron encoding region, a specialist element termed a retrotransposition-activated marker, or RAM. As the name suggests, this equates to an inactivated marker (typically a gene coding for an antibiotic resistance) which becomes activated during retrotransposition (re-location and insertion of the group II intron into its target site). The ClosTron RAM is based on the $\operatorname{ermB}$ gene (encoding resistance to erythromycin, Em), which allows for group II insertions to be selected on the basis of acquisition of resistance to Em, following plating of thiamphenicol resistant ClosTron plasmid transformants onto media supplemented with Em. Inactivation of $\operatorname{erm} B$ is accomplished by the insertion of a small region of DNA encompassing a group I intron (that of phage $t d$ ) into the structural gene. Group I introns are self-catalytically spliced from mRNA. However, splicing is orientation dependent, a mechanistic property that is beneficially exploited by inserting the group I intron into the ermB gene such that its orientation in the corresponding mRNA transcript does not allow splicing. Therefore functional ErmB protein cannot be produced from the mRNA. It follows that ClosTron plasmids (e.g., pMTL007C-E2) do not confer Em resistance on their clostridial hosts. When RNA transcripts encompassing the group II intron are produced from the opposite DNA strand, the $t d$ group I intron is in the correct orientation and is spliced from the RNP complex formed. As a consequence, insertion of the group II intron into the target site delivers a functional $\operatorname{ermB}$ to the genome, an event that can be directly selected on solidified media supplemented with Em. ${ }^{8,17}$ A schematic illustration of the process is shown in Figure 1.

\section{ClosTron Protocol Refinements}

The original ClosTron plasmid pMTL007

8 was largely modelled on the system 


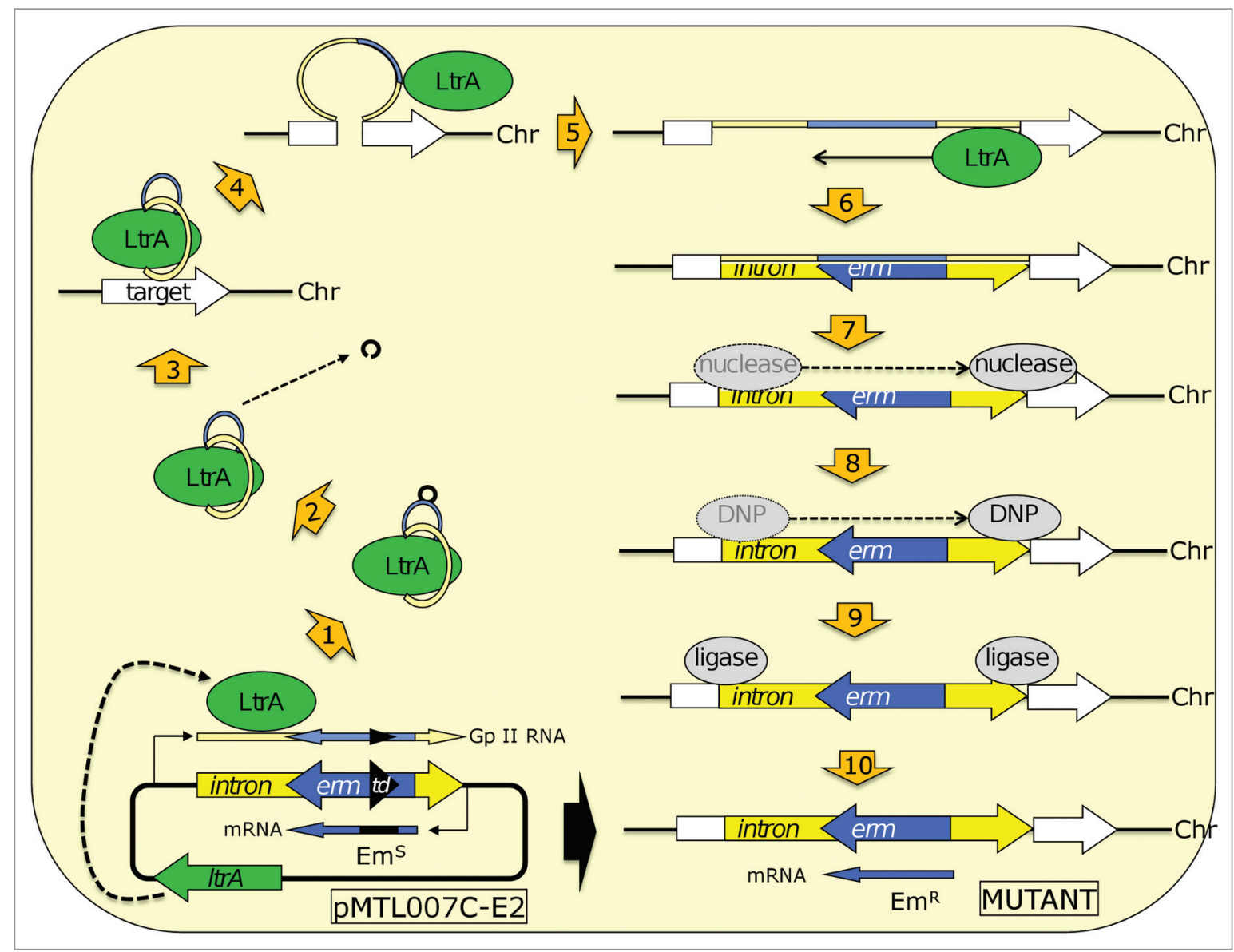

Figure 1. Schematic representation of mutant generation using the ClosTron. The ClosTron plasmid (in this example pMTL007C-E2 ${ }^{18}$ ) encompasses a group II intron encoding region (yellow) into which the ermB gene (blue) is inserted, which has been inactivated by the insertion of a small region of DNA (black) encompassing the phage $t d$ group I intron. The $t d$ intron can mediate its own splicing from RNA transcripts, but the process is orientation specific. The ItrA gene (green) which normally resides within the group II intron encoding region has be repositioned elsewhere on the plasmid. Transcription of the ermB gene results in an mRNA transcript containing the $t d$ group I intron insertion, but its orientation is such that self-catalytic splicing does not occur. It follows that PMTL007C-E2 does not confer erythromycin (Em) resistance (R) on the host cell, which is therefore sensitive (S). When the opposite DNA strand encompassing the group II intron region is transcribed, LtrA protein binds to the transcript leading to (A) the formation of a ribonuclear protein (RNP) complex. (B) As the td group I intron is now in the correct orientation, it is spliced out. (C) The RNP recognises and binds (by virtue of the re-targeted sequence incorporated into the group II intron encoding region) to specific sequences in the target gene within the chromosome (Chr). (D) LtrA "nicks" the DNA target and (E) inserts the RNA. (F) The reverse transcriptase activity of LtrA now synthesises the complementary DNA strand. (G) Host nucleases degrade the insert RNA and (H) DNA polymerase (DNP) synthesises the opposite DNA strand. (I) Host ligases seal the two gaps, leading to $(J)$ completion of the process, in which a functional erm $B$ gene is now present in the target gene, an event that is selectable due to acquisition of resistance to Em.

derived for, and sold for use in, E. coli. This plasmid pACD4K-C (http://www.sigmagenosys.com/targetron/) carried a ColE1 replicon, a kanamycin RAM and incorporated an IPTG inducible T7 promoter that mediated expression of the group II intron RNA. To ensure functionality in Clostridium spp the ColE1 replication region was substituted with that of the Clostridium butyricum plasmid pCB102, and the chloramphenicol marker used for selectable maintenance of the plasmid replaced with a clostridial catP gene which conferred resistance to thiamphenicol on cells harboring the plasmid. Finally, the T7 promoter was replaced with the promoter region of the Clostridium pasteurianum ferredoxin gene which had been derivatised to include a lac operator sequence. Transcription from the resultant fac promoter was repressed by LacI produced from a plasmid borne copy of the lacI gene, and induced by addition of exogenous IPTG.

Following its derivation, a number of pivotal refinements were introduced that considerably enhanced the system's utility. ${ }^{18}$ An overriding principle has been to ensure that all new plasmids conform to the format of the pMTL8000 modular plasmids, ${ }^{19}$ a series of ClostridiumE. coli shuttle vectors designed to facilitate the substitution and re-assembly of different plasmid component parts. This is achieved by localising the various components (e.g., antibiotic resistance marker, gram-positive and gram-negative replicon as well as application-specific modules) between two specific unique restriction sites. As an "application-specific module," the ClosTron was cloned between the $S b f \mathrm{I}$ and $A s c \mathrm{I}$ restriction enzyme sites. ${ }^{18}$ As experimental data ${ }^{8}$ 
clearly showed that there was no advantage to inducible control of group II RNA production, the fac promoter was replaced with a constitutive promoter, $f d x$, derived from the ferredoxin gene of Clostridium sporogenes. More importantly, this allowed the lacI gene to be removed from the plasmid backbone and as a consequence gave a considerable reduction in vector size. Other refinements concerned repeated use of the system and cargo delivery, but perhaps the most important innovation concerned the procedures used to generate re-targeted plasmids.

The original concept championed by Sigma Aldrich was that a computer algorithm at the TargeTron design site (http:// www.sigma-genosys.com/targetron/) was used to predict the alterations necessary for intron re-targeting within a $344 \mathrm{bp}$ fragment which could be inserted into the TargeTron or ClosTron vector between the unique Bsr GI and HindIII restriction sites. The generation of the fragment was accomplished using a single splicing by overlap extension (SOE) PCR in conjunction with an appropriate set of four primers (three of which are designed through the intron re-targeting algorithm, with a fourth universal primer) and a special template supplied as part of the Sigma Aldrich TargeTron kit. However, it was apparent to us that the most cost and time effective method of generating the re-targeted plasmids would be to have the $344 \mathrm{bp}$ fragment re-synthesized and cloned into the chosen ClosTron vector by an appropriate gene synthesis company, such as DNA2.0. Accordingly, we have implemented this strategy through the creation of the website www.clostron. com. To facilitate the process we have established a free to access, re-targeting design tool at this website based on the algorithm and data of Perutka et al. ${ }^{13}$ Using this route, the required plasmids can be available within 10-14 days following their design. Thereafter, depending on the growth rate of the clostridial species employed, mutants can be available within 5-7 days. Essential steps of the process are outlined in Figure 2. A more detailed description of the methodology involved may be found in the protocol of Kuehne and co-workers. ${ }^{20}$

\section{Repeated Use of the ClosTron}

Whilst ClosTrons incorporating an ermB::RAM considerably facilitate the isolation of mutants, the process is not without its drawbacks. Most notably, the isolation of multiple mutants is not possible, as once a mutant is made the cell has become resistant to Em. One solution is to use ClosTron plasmids that lack the RAM element, and simply screen for mutants either by appropriate PCR, or if possible by phenotypic assay. Such plasmids are now available, e.g., pMTL007C1. ${ }^{18}$ As an alternative solution, the ermB::RAM was derivatised to include flanking FRT sites which allowed, through the action of FLP recombinase, the excision of the intervening sequence. ${ }^{18}$ The resultant cells are Em sensitive due to excision of the erm $B$ gene and may therefore be used as a host for the derivation of further mutants using the ClosTron. The necessary enzyme is supplied by introducing a plasmid (e.g., pMTL85151-PPS-flp3) into the cell carrying a yeast-derived FLP recombinase gene. ${ }^{18}$ The utility of this facility was aptly demonstrated in the study of Steiner et al. ${ }^{21}$ where three cycles of the method were implemented to create triple mutants of C. acetobutylicum with insertions in three different orphan kinase genes. Inexplicably, in our laboratory at least, the successful "flipping out" of ermB from a ClosTron mutant using FLP recombinase has only ever been achieved in $C$. acetobutylicum. Thus despite repeated attempts, we have never been able to excise $\operatorname{erm} B$ in ClosTron mutants of either Clostridium difficile, C. sporogenes or Clostridium botulinum.

Theoretically, it should also be possible to create RAM elements of other antibiotic resistance genes. The essential requirement would be to have within the structural gene the specific exon sequence required for splicing of the $t d$ group I intron, G/ACCCAAGAGA (the group I intron sequence is simply inserted between the first and second nucleotide). Accordingly, the encoded protein responsible for antibiotic resistance must contain either of the following peptide sequences: DPRD/E, R/GPKR or L/M/V/S/P/T/ $\mathrm{A} / \mathrm{Q} / \mathrm{K} / \mathrm{E} / \mathrm{W} / \mathrm{R} / \mathrm{G} / \mathrm{TQEI} / \mathrm{M} / \mathrm{T} / \mathrm{N} / \mathrm{K} /$ $\mathrm{S} / \mathrm{R}$. In the case of the kanamycin and trimethroprim resistance genes used in E. coli TargeTrons, ${ }^{11}$ these exon specific sequences could be introduced into the coding sequence without any adverse effect on enzyme function. However, these markers cannot be used in clostridia, and no antibiotic resistance marker suitable for use in clostridia carries such peptide sequences. Indeed, as the required exon sequence could not be introduced into $\mathrm{erm} B$ without changing the encoded amino acid sequence, the ClosTron RAM element was made by adding an additional 12 amino acids to the N-terminus of the ErmB protein which carried the required exon sequence. ${ }^{8}$ Fortunately, these added amino acids were shown to have no discernible effect on function.

As an alternative we have successfully exploited a "pseudo-suicide" principle to generate group II intron insertions with the antibiotic resistance markers catP (encoding resistance to thiamphenicol) and aad9 (encoding resistance to spectinomycin). "Pseudo-suicide" is a term coined in our laboratory ${ }^{22}$ to describe a plasmid which is segregationally unstable because it replicates at a rate which is slower than that of the host chromosome. It follows that under selection for a plasmid-borne marker, integrant clones (those cells in which the marker becomes associated with the chromosome) can be enriched (rather than selected, as is the case for a suicide vector) from a population of cells. This is because the growth rate of integrant clones is not limited by the rate at which the pseudo-suicide vector can replicate and segregate into daughter cells. A classic example of this principle is in its use to derive mariner transposon mutants of C. difficile using plasmid pMTL-SC1, which incorporates the unstable $\mathrm{pBP} 1$ replicon. ${ }^{22}$ As only $1.3 \%$ of cells retain plasmids based on the $\mathrm{pBP} 1$ replicon at each generation in the absence of selection, cells in which transposition has occurred are readily enriched in the presence of thiamphenicol. ${ }^{22}$ We have, therefore, applied the same principle with a mobile group II intron by replacing the ermB::RAM marker with catP to generate double toxin $\mathrm{A} /$ toxin $\mathrm{B}$ mutant of $C$. difficile. ${ }^{23}$ Accordingly, a toxin B mutant was first generated using a re-targeted derivative of the plasmid pMTL007C-E2 
Figure 2. Flowchart illustrating the generation of ClosTron mutants. For simplicity, the process has been split into eight steps. (1) Choose a vector with appropriate replicon and antibiotic resistance markers for the Clostridium species to be modified. (2) Design the required re-targeted region for the gene to be inactivated using the design tool at www.clostron.com and order an appropriate ClosTron plasmid incorporating this sequence from DNA2.0. (3) On receipt of the re-targeted plasmid transfer to the desired clostridial host either via conjugation or electroporation. (4) Restreak purified transconjugants/transformants onto agar media supplemented with an antibiotic appropriate to the intron-specific selectable marker (e.g., erythromycin in case of the ermB::RAM) to select for integrants. It is crucial to isolate three independent mutants at this stage. (5) Derive preliminary evidence that the intron has inserted at the desired site using a PCR screen and appropriate primers. (6) Confirm insertion at the correct target site by Sange sequencing of the PCR amplified fragments of both junction points AND establish that there is only one intron insertion event in the cell by performing a Southern blot using intron-specific probes. (7) Undertake appropriate phenotypic characterization, on at least 2 out of the 3 mutants. (8) Finally, the mutant phenotype should be complemented, by introducing a wild type copy of the gene cloned in an appropriate vector of the pMTL8000 series.

(which carries catP as its selectable plasmid backbone marker), by isolating thiamphenicol resistant transconjugants, and then screening for erythromycin resistant clones indicative of insertion of the group II intron along with $\operatorname{erm} B$ into the $t c d B$ gene. Following loss of pMTL007C$\mathrm{E} 2$, and as a consequence catP, the cells are no longer resistant to thiamphenicol. A ClosTron plasmid re-targeted to the toxin A gene $(t c d A)$ was then generated using pMTL007S-C7. This vector carries the aad9 gene as the plasmid backbone marker, and the catP gene in place of the ermB::RAM marker. Its transfer into the $C$. difficile $t c d B$ mutant was therefore selected on the basis of acquisition of resistance to spectinomycin. Thereafter, repeated restreaking onto media supplemented with thiamphenicol, by virtue of the "pseudo-suicide" principle, resulted in the enrichment of cells in which the group II intron, along with the catP gene, had been inserted into $t c d A .{ }^{23}$ In a more recent study, we have taken this principle a step
8 easy steps to generate your ClosTron mutant

Select the most appropriate ClosTron 1 plasmid for the Clostridium to be modified

\section{2}

Design and order the retargeted

plasmid at www.clostron.com

\section{3}

Transfer the retargeted plasmid into clostridial host

(conjugation/transformation)

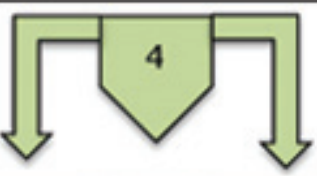

Isolate three independent integrants

5

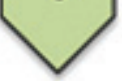

PCR screen to confirm mutants
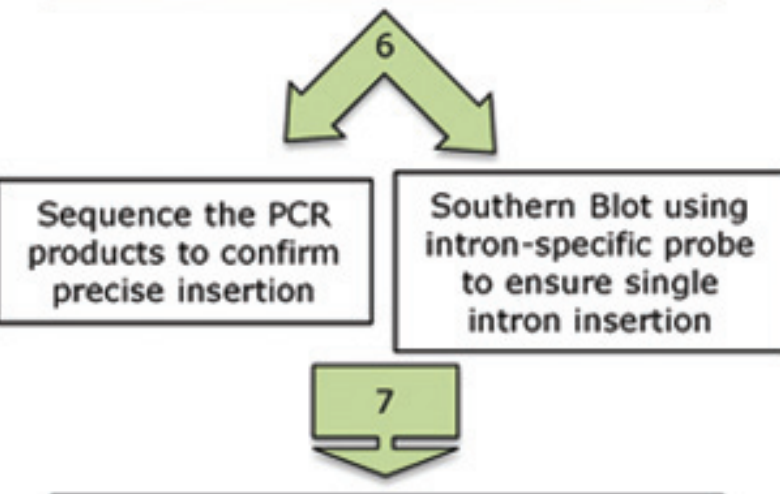

Perform phenotypic characterisation of at least two mutants

8

Complementation of mutant phenotype using pMTL 8000 vector 


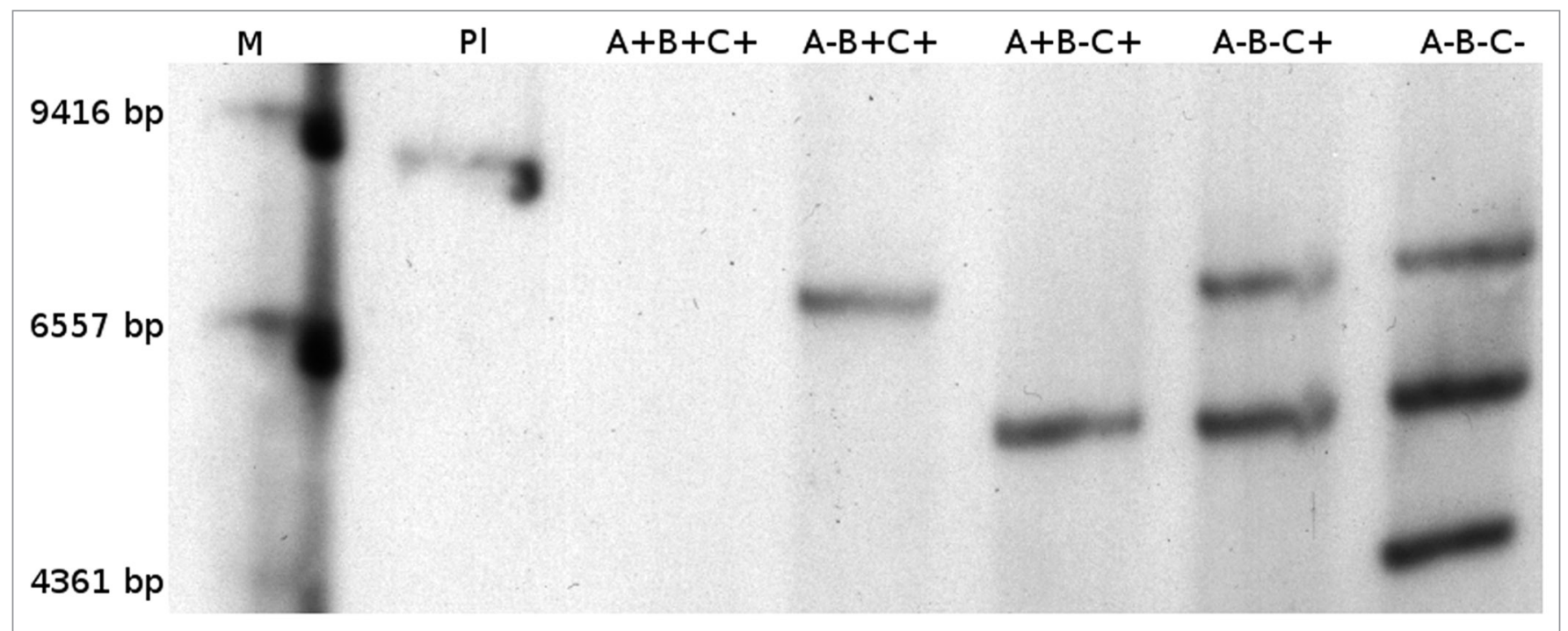

Figure 3. Southern blot of ClosTron mutants in C. difficile R20291. This Southern blot shows single, double and triple insertions in three toxin genes of $C$. difficile R20291. Insertions were made using either the original ermB::RAM, or the aad9 or catP ClosTrons described in the text. The parental strain carries $t c d A(A+)$ encoding for toxin $A, t c d B(B+)$ encoding for toxin $B$ and $c d t A(C+)$ encoding for the catalytic domain of the binary toxin. The Southern blot shows the ladder $(M$, Lambda-HindIII), followed by a plasmid control $(\mathrm{PI})$, the parental strain $(A+B+C+)$ which has no insertions and then a tcdA mutant $(A-B+C+)$, a $t c d B$ mutant $(A+B-C+)$, a $t c d A-t c d B$ double mutant ( $A-B-C+$ ) and a triple mutant, having ClosTron insertions in $t c d A$, $t c d B$ and $c d t A$ (A-B-C-).

further, by making a third mutation in a $t c d A, t c d B$ double mutant of $C$. difficile, by using a re-targeted plasmid based on pMTL007T-S7 which carries a tet $A$ gene as the plasmid backbone marker, and in which the ermB::RAM marker has been replaced by aad9 (SA Kuehne and NP Minton, unpublished data). In this case the enrichment of group II intron insertions was undertaken on media supplemented with spectinomycin. Figure 3 is a Southern blot showing single, double and triple ClosTron mutants of $C$. difficile made using this principle.

\section{Mutant Nomenclature}

One important aspect of the exploitation of the ClosTron resides in the implementation of consistency in the nomenclature of the mutants derived and in the information supplied in publications describing its use. ClosTron mutants are insertional, and therefore should not be mistakenly referred to as "deletion" mutants through the use of a delta $(\Delta)$ suffix/prefix. We suggest essential information that should be included is the identity of the ClosTron plasmid employed, the gene name or ID, the point of intron insertion and the orientation of the intron insertion. Finally the sequence of the re-targeted region used to generate the insertion should be given. So, for example, when creating a toxin A mutant in C. difficile strain R20291, the implementation of the Perutka algorithm ${ }^{13}$ at www.clostron.com suggests a possible insertion site in the sense orientation after nucleotide 1584 . The mutant created using the appropriately generated re-targeted ClosTron plasmid should, in keeping with two published nomenclatures, ${ }^{24,25}$ be named: $t c d A 1584 \mathrm{~s}:$ :CT. From this it may be inferred that the mutation is in the $t c d A$ gene and that the ClosTron (CT) insertion occurs immediately after nucleotide 1584 (nucleotide position 1 being the initial base of the translational start codon) and has inserted in the sense orientation, hence "s." It would also be useful to indicate the Clostridium strain used. Perhaps the name could be extended to reflect, in this case, that the mutation was made in C. difficile strain R20291 to yield CdiR20291-tcdA1584s::CT.

Further essential information that should be provided is the identity of the ClosTron plasmid employed (e.g., pMTL007C-E2, pMTL007S-C7 or pMTL007T-S7) together with the sequence of the re-targeted region used to direct the insertion of the intron, in the case of CdiR20291-tcdA1584s::CT, TGG AGC TTT GAT CAA GCA AGT GCA AAA TAT<intron>CAA TTT GAG AAA TAT. With this information researchers are fully informed as to exactly how the mutant was made and may, if they so desire, recreate it independently. Finally, to avoid unnecessary use of resources, it would be useful if researchers document the identity of those re-targeted sequences which were tested without success.

\section{Conclusions}

ClosTron technology is now in widespread use within the research community and is finding broad application in both pathogens and industrially important species alike. By way of example, it has been used to establish the role of bacterial factors (toxins, flagella and adhesins) in infection, ${ }^{23,26-29}$ to garner a greater understanding of the role and activities of enzymes in primary metabolism, ${ }^{30-33}$ to begin to elucidate mechanistic details of the developmental process of spore formation/ germination ${ }^{21,34,35}$ and provide fundamental information on regulatory processes important in virulence factor and metabolite production. ${ }^{36-39}$ Its availability has provided the research community with a 
much needed tool for the rapid generation of mutants. Recently, however, new methodologies have been developed based on allelic exchange which now provide the facility to make precise changes to the genome, avoiding the issues of polar effects associated with insertional mutagens. ${ }^{40-42}$

\section{References}

1. Rings DM. Clostridial disease associated with neurologic signs: tetanus, botulism and enterotoxemia. Vet Clin North Am Food Anim Pract 2004; 20:37991; PMID:15203231; http://dx.doi.org/10.1016/j. cvfa.2004.02.006.

2. Cartman ST, Heap JT, Kuehne SA, Cockayne A, Minton NP. The emergence of 'hypervirulence' in Clostridium difficile. Int J Med Microbiol 2010; 300:387-95; PMID:20547099; http://dx.doi. org/10.1016/j.ijmm.2010.04.008.

3. Songer JG. Clostridia as agents of zoonotic disease. Vet Microbiol 2010; 140:399-404; PMID:19682805; http://dx.doi.org/10.1016/j.vetmic.2009.07.003.

4. Dürre P. Handbook on Clostridia. New York: CRC Press 2005.

5. Demain AL, Newcomb M, Wu JHD. Cellulase, clostridia and ethanol. Microbiol Mol Biol Rev 2005; 69:124-54; PMID:15755956; http://dx.doi. org/10.1128/MMBR.69.1.124-54.2005.

6. Minton NP, Winzer K. Solvent production-not to be sniffed at! Biobutanol: $21^{\text {st }}$ century biofuel. Biochemist 2011; 33:8-13.

7. Heap JT, Cartman ST, Pennington OJ, Cooksley CM, Scott JC, Blount B, et al. Development of genetic knock-out systems for clostridia. In: Bruggermann H, Gottschalk G, Eds. Clostridia: Molecular biology in the post-genomic era. Norfolk: Caister Academic Press 2008; 179-98.

8. Heap JT, Pennington OJ, Cartman ST, Carter GP, Minton NP. The ClosTron: a universal gene knockout system for the genus Clostridium. J Microbiol Methods 2007; 70:452-64; PMID:17658189; http:// dx.doi.org/10.1016/j.mimet.2007.05.021.

9. Mohr G, Smith D, Belfort M, Lambowitz AM. Rules for DNA target-site recognition by a lactococcal group II intron enable retargeting of the intron to specific DNA sequences. Genes Dev 2000; 14:55973; PMID:10716944; http://dx.doi.org/10.1101/ gad.14.5.559.

10. Karberg M, Guo H, Zhong J, Coon R, Perutka J, Lambowitz AM. Group II introns as controllable gene targeting vectors for genetic manipulation of bacteria. Nat Biotechnol 2001; 19:1162-7; PMID:11731786; http://dx.doi.org/10.1038/nbt1201-162.

11. Zhong J, Karberg M, Lambowitz AM. Targeted and random bacterial gene disruption using a group II intron (targetron) vector containing a retrotransposition-activated selectable marker. Nucleic Acids Res 2003; 31:1656-64; PMID:12626707; http://dx.doi. org/10.1093/nar/gkg248.

12. Lambowitz AM, Zimmerly S. Mobile group II introns. Annu Rev Genet 2004; 38:1-35; PMID:15568970; http://dx.doi.org/10.1146/ annurev.genet.38.072902.091600.

13. Perutka J, Wang W, Goerlitz D, Lambowitz AM. Use of computer-designed group II introns to disrupt Escherichia coli DExH/D-box protein and DNA helicase genes. J Mol Biol 2004; 336:42139; PMID:14757055; http://dx.doi.org/10.1016/j. jmb.2003.12.009.

14. Chen Y, Caruso L, McClane B, Fisher D, Gupta P. Disruption of a toxin gene by introduction of a foreign gene into the chromosome of Clostridium perfringens using targetron-induced mutagenesis. Plasmid 2007; 58:182-9; PMID:17553563; http:// dx.doi.org/10.1016/j.plasmid.2007.04.002.
Nonetheless, ClosTron technology remains the method of choice when it is desirable to rapidly derive mutant phenotypes with minimum operator input.

15. Shao L, Hu S, Yang Y, Gu Y, Chen J, Yang Y, et al. Targeted gene disruption by use of a group II intron (targetron) vector in Clostridium acetobutylicum. Cell Res 2007; 17:963-5; PMID:17971808; http://dx.doi. org/10.1038/cr.2007.91.

16. Tolonen AC, Chilaka AC, Church GM. Targeted gene inactivation in Clostridium phytofermentan shows that cellulose degradation requires the family 9 hydrolase Cphy3367. Mol Microbiol 2009; 74:1300 13; PMID:19775243; http://dx.doi.org/10.1111/ j.1365-2958.2009.06890.x.

17. Heap JT, Cartman ST, Kuehne SA, Cooksley C, Minton NP. ClosTron-targeted mutagenesis. Methods Mol Biol 2010; 646:165-82; PMID:20597009; http://dx.doi.org/10.1007/978-1-60327-365-7_11.

18. Heap JT, Kuehne SA, Ehsaan M, Cartman ST, Cooksley CM, Scott JC, et al. The ClosTron: Mutagenesis in Clostridium refined and streamlined. J Microbiol Methods 2010; 80:49-55; PMID:19891996; http://dx.doi.org/10.1016/j. mimet.2009.10.018.

19. Heap JT, Pennington OJ, Cartman ST, Minton NP. A modular system for Clostridium shuttle plasmids. J Microbiol Methods 2009; 78:79-85; PMID:19445976; http://dx.doi.org/10.1016/j. mimet.2009.05.004.

20. Kuehne SA, Heap JT, Cooksley CM, Cartman ST, Minton NP. ClosTron-mediated engineering of Clostridium. Methods Mol Biol 2011; 765:389-407; PMID:21815105; http://dx.doi.org/10.1007/978-161779-197-0_23.

21. Steiner E, Dago AE, Young DI, Heap JT, Minton NP, Hoch JA, et al. Multiple orphan histidine kinases interact directly with Spo0A to control the initiation of endospore formation in Clostridium acetobutylicum. Mol Microbiol 2011; 80:641-54; PMID:21401736; http://dx.doi.org/10.1111/j.13652958.2011.07608.x.

22. Cartman ST, Minton NP. A mariner-based transposon system for in vivo random mutagenesis of Clostridium difficile. Appl Environ Microbiol 2010; 76:1103-9; PMID:20023081; http://dx.doi. org/10.1128/AEM.02525-09.

23. Kuehne SA, Cartman ST, Heap JT, Kelly ML, Cockayne A, Minton NP. The role of toxin A and toxin $\mathrm{B}$ in Clostridium difficile infection. Nature 2010; 467:711-3; PMID:20844489; http://dx.doi. org/10.1038/nature09397.

24. Demerec M, Adelberg EA, Clark AJ, Hartman PE. A proposal for a uniform nomenclature in bacterial genetics. Genetics 1966; 54:61-76; PMID:5961488.

25. Campbell A, Starlinger P, Berg DE, Botstein D, Lederberg EM, Novick RP, et al. Nomenclature of transposable elements in prokaryotes. Plasmid 1979; 2:466-73; PMID:384423; http://dx.doi. org/10.1016/0147-619X(79)90030-1.

26. Barketi-Klai A, Hoys S, Lambert-Bordes S, Collignon A, Kansau I. Role of fibronectin-binding protein $\mathrm{A}$ in Clostridium difficile intestinal colonization. J Med Microbiol 2011; 60:1155-61; PMID:21349990; http://dx.doi.org/10.1099/jmm.0.029553-0.

27. Kirby JM, Ahern H, Roberts AK, Kumar V, Freeman Z, Acharya KR, et al. Cwp84, a surface-associated cysteine protease, plays a role in the maturation of the surface layer of Clostridium difficile. J Biol Chem 2009; 284:34666-73; PMID:19808679; http:// dx.doi.org/10.1074/jbc.M109.051177.

\section{Acknowledgments}

Work in the author's laboratory was supported by the Biotechnology and Biological Sciences Research Council (BB/F003390/1, BB/G016224/1, BB/ E021271/1) and the Medical Research Council (G0601176).

28. Emerson JE, Reynolds CB, Fagan RP, Shaw HA, Goulding D, Fairweather NF. A novel genetic switch controls phase variable expression of $\mathrm{CwpV}$, a Clostridium difficile cell wall protein. Mol Microbio 2009; 74:541-56; PMID:19656296; http://dx.doi. org/10.1111/j.1365-2958.2009.06812.x.

29. Dingle TC, Mulvey GL, Armstrong GD. Mutagenic analysis of the Clostridium difficile flagellar proteins, FliC and FliD, and their contribution to virulence in hamsters. Infect Immun 2011; 79:40617; PMID:21788384; http://dx.doi.org/10.1128/ IAI.05305-11.

30. Lehmann D, Lütke-Eversloh T. Switching Clostridium acetobutylicum to an ethanol producer by disruption of the butyrate/butanol fermentative pathway. Metab Eng 2011; 13:464-73; PMID:21549853; http://dx.doi.org/10.1016/j.ymben.2011.04.006.

31. Cai G, Jin B, Saint C, Monis P. Genetic manipulation of butyrate formation pathways in Clostridium butyricum. J Biotechnol 2011; 155:269-74, PMID:21787814; http://dx.doi.org/10.1016/j.jbiotec.2011.07.004

32. Lehmann D, Hönicke D, Ehrenreich A, Schmidt $\mathrm{M}$, Weuster-Botz D, Bahl $\mathrm{H}$, et al. Modifying the product pattern of Clostridium acetobutylicum: physiological effects of disrupting the acetate and acetone formation pathways. Appl Microbiol Biotechnol 2012; 94:743-54; PMID:22246530; http://dx.doi. org/10.1007/s00253-011-3852-8.

33. Kuit W, Minton NP, López-Contreras AM, Eggink G. Disruption of the acetate kinase (ack) gene of Clostridium acetobutylicum results in delayed acetate production. Appl Microbiol Biotechnol 2012; 94:729-41; PMID:22249720; http://dx.doi. org/10.1007/s00253-011-3848-4.

34. Burns DA, Heap JT, Minton NP. SleC is essential for germination of Clostridium difficile spores in nutrient-rich medium supplemented with the bile salt taurocholate. J Bacteriol 2010; 192:65764; PMID:19933358; http://dx.doi.org/10.1128/ JB.01209-09.

35. Underwood S, Guan S, Vijayasubhash V, Baines SD, Graham L, Lewis RJ, et al. Characterization of the sporulation initiation pathway of Clostridium difficile and its role in toxin production. J Bacteriol 2009; 191:7296-305; PMID:19783633; http://dx.doi org/10.1128/JB.00882-09.

36. Söderholm H, Lindström M, Somervuo P, Heap J, Minton NP, Lindén J, et al. cspB encodes a major cold shock protein in Clostridium botulinum ATCC 3502. Int J Food Microbiol 2011; 146:23-30; PMID:21367479; http://dx.doi.org/10.1016/j.ijfoodmicro.2011.01.033.

37. Antunes A, Martin-Verstraete I, Dupuy B. CcpAmediated repression of Clostridium difficile toxin gene expression. Mol Microbiol 2011; 79:882-99; PMID:21299645; http://dx.doi.org/10.1111/j.13652958.2010.07495.x.

38. Cooksley CM, Davis IJ, Winzer K, Chan WC, Peck MW, Minton NP. Regulation of neurotoxin production and sporulation by a Putative agrBD signaling system in proteolytic Clostridium botulinum. Appl Environ Microbiol 2010; 76:4448 60; PMID:20453132; http://dx.doi.org/10.1128/ AEM.03038-09. 
39. Steiner E, Scott J, Minton NP, Winzer K. An agr quorum sensing system regulates granulose formation and sporulation in Clostridium acetobutylicum. Appl Environ Microbiol 2012; 78:111322; PMID:22179241; http://dx.doi.org/10.1128/ AEM.06376-11.

40. Nariya H, Miyata S, Suzuki M, Tamai E, Okabe A. Development and application of a method for counter selectable in-frame deletion in Clostridium perfringens. Appl Environ Microbiol 2011; 77:1375 82; PMID:21183644; http://dx.doi.org/10.1128/ AEM.01572-10.
41. Heap JT, Ehsaan M, Cooksley CM, Ng YK, Cartman $\mathrm{ST}$, Winzer $\mathrm{K}$, et al. Integration of DNA into bacterial chromosomes from plasmids without a counterselection marker. Nucleic Acids Res 2012; 40:59; PMID:22259038; http://dx.doi.org/10.1093/nar/ gkr1321.

42. Cartman ST, Kelly ML, Heeg D, Heap JT, Minton NP. Precise manipulation of the Clostridium difficile chromosome reveals a lack of association between $t c d C$ genotype and toxin production. Appl Environ Microbiol 2012; 20; PMID: 22522680; http:// dx.doi.org/10.1128/AEM.00249-12. 